\title{
Rencana penataan Promenade di Pantai Padang Galak, Desa Kesiman Petilan, Kecamatan Denpasar Timur, Kota Denpasar
}

\author{
I Gusti Agung Ngurah Prabawa ${ }^{1}$, Lury Sevita Yusiana ${ }^{1 *}$, Ida Ayu Mayun² \\ 1Program Studi Arsitektur Pertamanan, Fakultas Pertanian, Universitas Udayana, JI. P.B. Sudirman, \\ Denpasar, Indonesia \\ ${ }_{2}^{2}$ Program Studi Agroekoteknologi, Fakultas Pertanian, Universitas Udayana, Jl. P.B. Sudirman, Denpasar, \\ Indonesia
}

Email: lury.yusiana@unud.ac.id

\begin{abstract}
Plan for Arrangement of Promenade in Padang Galak Beach, Kesiman Petilan Village, East Denpasar District, Denpasar City. Padang Galak Beach is one of beach in Denpasar City that has a promenade as an access to human circulation. This promenade is well-located on Padang Galak Beach, but it is less organized and its potential has not been maximized. This study aims to identify and analyze the potential and constraints of physical aspects, vegetation, and activities on the Padang Galak Beach Promenade and conceptualize planning on the site. The study used survey methods with data collection techniques through observation, interviews, literature studies and questionnaires. The stages of this study were based on landscape planning which includes inventory, analysis, synthesis and conceptualization. The results showed that the basic concept used in this planning was intended to accommodate visitors in carrying out recreational and sports activities. The basic concept then become development concept that includes the concepts of space, the concept of circulation and the concept of green. The concept of space includes active and passive space, the concept of circulation includes two distribution between cyclist and promenades, the concept of green includes the use of vegetation with types of groundcover and shade trees. This arrangement plan was expected to organize and develop the Padang Galak Beach area.
\end{abstract}

Keywords: padang galak beach, arrangement plan, promenade, site.

\section{Pendahuluan}

Tepi Pantai Padang Galak terdapat promenade atau ruang pejalan kaki di sisi air yang langsung terhubung dengan Pantai Matahari Terbit. Promenade ini biasanya digunakan oleh masyarakat yang berkunjung untuk berjalan kaki, jogging dan bersepeda. Tanggul pengaman pantai dan promenade di Pantai Padang Galak dibuat oleh Balai Wilayah Sungai Bali-Penida pada tahun 2007. Promenade ini memiliki ukuran panjang mencapai 1,53 km dan lebar 2,2 $\mathrm{m}$. Tujuan dibuatnya promenade ini sebagai akses dari tim pelaksana Balai Wilayah Sungai Bali-Penida saat melakukan inspeksi dalam memantau konstruksi promenade maupun tanggul pengaman pantai yang berfungsi sebagai penahan dari terjangan air laut dan menjadi pembatas pantai antara ruang privat dan ruang publik. Promenade ini juga dapat digunakan bagi masyarakat untuk berjalan kaki, jogging, dan bersepeda (Balai Wilayah Sungai Bali-Penida, 2017).

Kondisi di area promenade Pantai Padang Galak ini kurang tertata dengan maksimal. Kurang tertatanya promenade pada tepi Pantai Padang Galak ini terlihat dari aspek vegetasi, fisik, dan aktivitas pengguna di area tersebut. Permasalahan dari aspek vegetasi seperti terdapat jenis tanaman merambat, rerumputan dan semak yang menutupi area promenade yang terlihat tidak bagus dipandang serta kurangnya tanaman peneduh tapak. Kurangnya tanaman peneduh berupa pohon dapat mengurangi kenyamanan pengunjung terutama saat siang dan menjelang sore hari. Aspek fisik yang dapat terlihat dari promenade Pantai Padang Galak ini yaitu terdapat beberapa fasilitas seperti lampu penerangan, tempat sampah, dan papan pemberitahuan yang hanya terdapat di bagian area awal memasuki pantai khususnya di dekat taman cemara Pantai Padang Galak serta untuk fasilitas penunjang aktivitas lain tidak ada. Promenade Pantai Padang Galak ini juga memiliki kekurangan lainnya, yaitu area tapak yang kurang lebar untuk dapat digunakan 
aktivitas jalan kaki, jogging dan bersepeda dalam satu area serta tidak ada tanda sebagai pembatas antara ruang khusus untuk pengguna sepeda maupun pejalan kaki yang dapat mengakibatkan kurang nyaman.

Promenade merupakan akses sirkulasi pejalan kaki pengunjung Pantai Padang Galak yang berada di lokasi strategis yaitu di daerah Kota Denpasar dan memiliki pemandangan alam yang bagus. Penelitian ini diperlukan untuk dapat menganalisis dan sintesis potensi, kendala, amenity serta danger signal yang digunakan dalam rencana penataan promenade Pantai Padang Galak ini agar lebih terlihat menarik dan nyaman untuk dikunjungi.

\section{Metode}

\subsection{Tempat dan Waktu Penelitian}

Penelitian dilaksanakan pada bulan September 2017 sampai bulan Maret 2018 dengan lokasi penelitian pada promenade di tepi Pantai Padang Galak, Desa Kesiman Petilan, Kecamatan Denpasar Timur, Kota Denpasar, Provinsi Bali. Batas pantai di sebelah timur laut yaitu Pantai Tangtu dan batas pantai di sebelah selatan yaitu Pantai Matahari Terbit. Rencana penataan pada penelitian ini sepanjang 1,15 km di mulai dari bagian taman cemara yang berada di area tempat awal memasuki Pantai Padang Galak sampai pada bagian selatan yang berbatasan dengan Pantai Matahari Terbit. Lokasi penelitian dapat dilihat pada Gambar 1.

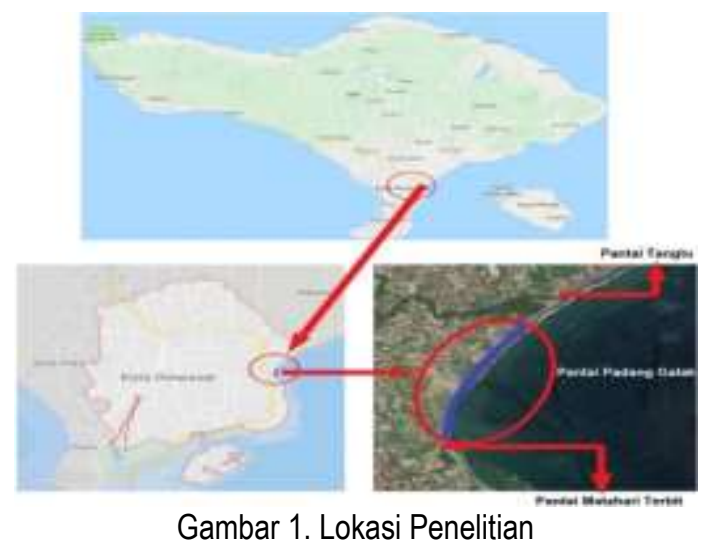

\section{$2.2 \quad$ Alat Penelitian}

Alat yang digunakan dalam pelaksanaan penelitian yaitu alat tulis, kamera, meteran, kuesioner, laptop dengan piranti lunak aplikasi autocad 2017, sketchup 2015, google earth, dan google map.

\subsection{Metode}

Metode yang digunakan dalam penelitian ini yaitu metode survei. Jenis data yang digunakan, yaitu data primer yang diperoleh dari pengamatan langsung di lapangan dan melakukan wawancara dengan pihak pengelola seperti Balai Wilayah Sungai Bali-Penida, data sekunder berupa pengumpulan data yang diperoleh dari studi pustaka, yaitu data yang bersumber dari buku-buku, jurnal, makalah, dan media internet.Teknik pengumpulan data yang digunakan dalam penelitian ini yaitu, pengamatan (observasi), wawancara, studi kepustakaan, dan kuesioner. Kuesioner ditujukan kepada pengunjung dengan pertanyaan terkait aktivitas, visual tapak, kenyamanan beraktivitas, fasilitas, kebersihan, pemeliharaan promenade, vegetasi yang diinginkan, dan fasilitas yang diinginkan.

\section{Hasil dan pembahasan}

\subsection{Gambaran Umum Lokasi Penelitian}

Pantai Padang Galak berada di Desa Kesiman Petilan, Kecamatan Denpasar Timur, Kota Denpasar. Batas-batas wilayah administratif Desa Kesiman Petilan yaitu, sebelah utara berbatasan dengan Kelurahan Tonja, sebelah timur berbatasan dengan Desa Kesiman Kertalangu, sebelah selatan berbatasan dengan Desa Sanur Kaja, Sebelah barat berbatasan dengan Kelurahan Kesiman. Jarak yang ditempuh untuk mengakses 
Desa Kesiman Petilan dari pusat Kota Denpasar yaitu sekitar $3 \mathrm{~km}$ dan jarak yang ditempuh untuk mengakses Pantai Padang Galak dari pusat Kota Denpasar sekitar $8 \mathrm{~km}$.

Pantai Padang Galak berada di Desa Kesiman Petilan, Kecamatan Denpasar Timur memiliki suhu ratarata $27,5^{\circ} \mathrm{C}$ pada tahun 2017 . Suhu tertinggi terjadi pada bulan November yaitu mencapai $37,0^{\circ} \mathrm{C}$ dan suhu terendah terjadi pada bulan Februari yaitu mencapai $18,3^{\circ} \mathrm{C}$, kelembapan rata-rata $78,8 \%$ (Badan Pusat Statistik Kota Denpasar, 2017).

Berdasarkan data dari Dinas Hidro-Oseanografi TNI Angkatan Laut pada buku Daftar Pasang Surut Kepulauan Indonesia tahun 2017 pada lokasi pengukuran Benoa menunjukkan pasang air laut mencapai titik tertinggi yaitu 2,7 m yang terjadi pada bulan Maret, April, Mei, Juni, Oktober, November, dan Desember dan surut air laut mencapai titik terendah yaitu $-0,1 \mathrm{~m}$ yang terjadi pada bulan Januari, April, Mei, Juni, Juli, November dan Desember.

\subsection{Inventarisasi tapak}

Promenade Pantai Padang Galak memiliki ukuran panjang mencapai 1,53 km dan lebar 2,2 $\mathrm{m}$. Ketinggian konstruksi tanggul pengaman pantai yang pada puncaknya berada di area pejalan kaki atau promenade dari kaki pondasi paling atas tersebut mencapai $5 \mathrm{~m}$. Material yang digunakan pada permukaan promenade Pantai Padang Galak yaitu paving block.

Promenade di Pantai Padang Galak pada area pinggirannya terdapat vegetasi yang tumbuh dengan baik. Berdasarkan pengamatan langsung ke lokasi penelitian, terdapat berbagai tanaman seperti rumput teki (Cyperus rotundus), pandan duri (Pandanus tectorius), widuri (Calotropis gigantea), jayanti (Sesbania sesban), waru (Hibiscus tiliaceus), ketapang (Terminalia catappa) serta terdapat tanaman penyusun ekosistem pantai berpasir seperti katang-katang (Ipomoea pes-caprae), dan kacang laut (Canavalia maritime).

Promenade Pantai Padang Galak terdapat berbagai aktivitas yang dilakukan pada tapak. Berbagai aktivitas yang ada di promenade Pantai Padang Galak adalah jalan santai, jogging, bersepeda, duduk (bersantai), berjualan. Fungsi promenade lainnya adalah sebagai akses untuk memantau konstruksi tanggul pengaman pantai dan promenade yang dilakukan oleh tim pelaksana Balai Wilayah Sungai Bali-Penida. Melalui kuesioner penelitian terhadap 30 responden pengunjung dengan rentang usia 17 sampai 60 tahun menunjukkan ragam latar belakang pengunjung yaitu, sebagai pegawai swasta, mahasiswa, dan ibu rumah tangga. Pengunjung lebih banyak yang berasal dari Kota Denpasar.

Promenade Pantai Padang Galak terkesan kurang menarik secara visual terlihat dari beberapa titik. Lokasi promenade di bagian selatan banyak ditumbuhi oleh berbagai vegetasi seperti semak, rerumputan, tanaman penutup tanah yang menutupi sebagian area dari promenade. Tumbuhan di pinggir promenade ini tampak tidak tertata dan kurang baik untuk dilihat.

Promenade Pantai Padang Galak memiliki fasilitas pendukung yang masih sedikit. Fasilitas pendukung seperti papan pemberitahuan, tempat sampah, serta lampu penerangan dan papan evakuasi kebencanaan sudah tersedia akan tetapi jumlahnya masih terbatas dan hanya terdapat di bagian area awal memasuki pantai khususnya di dekat taman cemara Pantai Padang Galak saja. Area promenade di bagian selatan yang dekat dengan Pantai Matahari Terbit belum tersedia fasilitas pendukung tapak.

\subsection{Analisis dan Sintesis Tapak}

\subsubsection{Promenade}

Ditinjau dari aktivitas tapak yang ada, promenade ini memiliki potensi untuk dapat dikembangkan sebagai tempat rekreasi maupun berolahraga, selain fungsi utama promenade ini sebagai akses untuk memantau konstruksi tanggul pengaman pantai dan promenade Pantai Padang Galak oleh tim pelaksana Balai Wilayah Sungai Bali-Penida. Secara umum ketinggian promenade ini relatif sudah tinggi dikarenakan elevasi puncak konstruksi berada pada level yang lebih tinggi dari pasang tertinggi air laut (Balai Wilayah Sungai BaliPenida). Berdasarkan data Dinas Hidro-Oseanografi TNI Angkatan Laut pada buku Daftar Pasang Surut Kepulauan Indonesia tahun 2017, lokasi pengukuran Benoa menunjukkan pasang air laut mencapai titik tertinggi yaitu mencapai $2,7 \mathrm{~m}$.

Berdasarkan pengamatan langsung pada lokasi tapak terdapat sejumlah kendala seperti, pengunjung yang mengendarai sepeda motor di atas promenade dan memarkirkan sepeda motor pada promenade. Area sirkulasi promenade memiliki lebar 2,2 $\mathrm{m}$ dan pada bagian jembatan penghubung promenade memiliki lebar 2 $\mathrm{m}$. Lebar sirkulasi promenade tersebut dapat membuat pengunjung kurang leluasa untuk melakukan aktivitas 
seperti jogging, jalan santai, dan bersepeda pada saat yang bersamaan dalam satu area. Lebar minimal jalur jogging, jalan santai, dan bersepeda untuk digunakan pada saat bersamaan dalam satu area, yaitu $3 \mathrm{~m}$ pada ketentuan Time Saver Standards for Landscape Architecture (Harris dan Dines, 1998).

Pengunjung mengendarai sepeda motor di atas promenade dan memarkirkan kendaraan pada promenade yang semestinya tidak boleh dilakukan disebabkan karena ada beberapa titik di area tertentu memiliki timbunan tanah cukup tinggi yang dapat dengan mudah dilalui oleh pengguna sepeda motor untuk naik ke atas area promenade. Timbunan tanah pada pinggir area promenade memiliki fungsi untuk memperkokoh konstruksi tanggul pengaman pantai dan promenade. Pengguna memarkirkan sepeda motor pada area promenade dapat dilihat pada Gambar 2.

Solusi untuk dapat meminimalisir kendala pada pengunjung yang mengendarai sepeda motor di atas promenade dan memarkirkan kendaraan pada promenade tersebut, seperti mengurangi sedikit timbunan tanah di pinggir area agar tidak setara dengan tinggi promenade serta membuat anak tangga di beberapa bagian tertentu untuk memudahkan pengunjung saat naik dan turun dari promenade. Solusi untuk meminimalisir kendala pada area promenade dan bagian jembatan penghubung promenade yang kurang lebar untuk mendukung pengembangan aktivitas aktif seperti jogging, jalan santai serta bersepeda yaitu dengan menambah lebar promenade yang sesuai dengan ketentuan pada Time Saver Standards for Landscape Architecture (Harris dan Dines, 1998), disebutkan bahwa ukuran lebar minimum promenade adalah $3 \mathrm{~m}$ untuk digunakan aktivitas berjalan kaki serta bersepeda dalam satu area. Lebar ukuran minimum tersebut akan dikembangkan hingga mencapai 4,6 m untuk dapat lebih leluasa digunakan termasuk juga pada lebar jembatan dengan ukuran yang sama. Promenade terbagi atas dua sirkulasi berbeda yaitu, sirkulasi untuk pejalan kaki dengan ukuran lebar 2,2 $\mathrm{m}$ dan sirkulasi untuk bersepeda dengan ukuran lebar 2,4 $\mathrm{m}$.

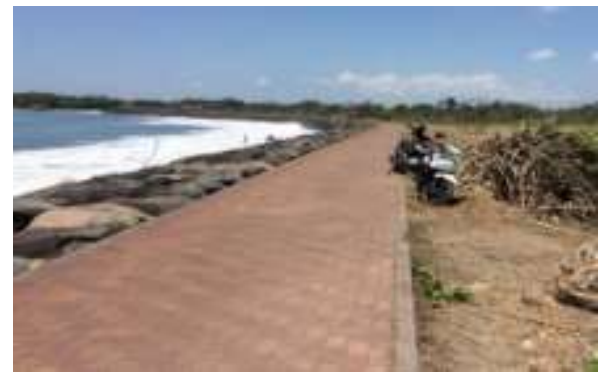

Gambar 2. Pengguna memarkirkan sepeda motor pada area Promenade

\subsubsection{Vegetasi}

Berdasarkan hasil inventarisasi penelitian jenis tanaman yang tumbuh pada lokasi penelitian seperti rumput teki (Cyperus rotundus), pandan duri (Pandanus tectorius), jayanti (Sesbania sesban), widuri (Calotropis gigantea), waru (Hibiscus tiliaceus) katang-katang (Ipomoea pes-caprae), kacang laut (Canavalia maritime), dan ketapang (Terminalia catappa). Vegetasi yang ditemui seperti katang-katang (Ipomoea pescaprae), kacang laut (Canavalia maritime) dan ketapang (Terminalia catappa) merupakan vegetasi daerah pesisir yang memiliki potensi untuk digunakan dalam penataan promenade dari sisi tata hijau

Iklim memberikan kenyamanan (amenity) yang dapat mempengaruhi pengunjung saat berada pada tapak. Menurut Laurie (1986) iklim ideal bagi manusia adalah udara yang bersih dengan suhu udara kurang lebih $27^{\circ} \mathrm{C}$ sampai dengan $28^{\circ} \mathrm{C}$, dan kelembapan udara antara $40 \%$ sampai dengan $75 \%$. Suhu udara Pantai Padang Galak relatif ideal dengan suhu udara rata-rata $27,5^{\circ} \mathrm{C}$ namun pada keadaan suhu maksimum dapat mencapai 37,00 (Badan Pusat Statistik Kota Denpasar, 2017) lokasi tapak akan terasa panas dan sedikitnya vegetasi peneduh menyebabkan tapak ini terasa kurang nyaman terutama saat siang hari dan menjelang sore hari. Solusi untuk dapat memberi rasa nyaman pengunjung pada tapak seperti menanam vegetasi peneduh yang dapat melindungi pengunjung dari suhu yang panas dan terhindar dari teriknya sinar matahari terutama saat melewati promenade pada siang hari dan menjelang sore hari.

\subsubsection{Pengunjung}

Berdasarkan hasil kuesioner penelitian dengan responden berjumlah 30 orang, pengunjung yang melakukan aktivitas di promenade ini lebih banyak melakukan kegiatan olahraga dengan persentase nilai $67 \%$ 
dan kegiatan berekreasi mendapat nilai sebanyak $33 \%$ sebagai nilai tertinggi kedua setelah kegiatan olahraga. Penataan secara visual dianggap cukup menarik (40\%), faktor kenyamanan melakukan aktivitas terhadap kurangnya vegetasi peneduh pengunjung menganggap kurang nyaman (44\%), pengunjung menganggap fasilitas pada promenade kurang memadai $(74 \%)$, kebersihan area promenade pengunjung menganggap kurang $(47 \%)$, pengunjung menganggap dari segi pemeliharaan promenade cukup baik (53\%).

Persepsi pengunjung melalui kuesioner menunjukkan beberapa hal pada tapak menjadi kendala seperti kurangnya vegetasi (peneduh) yang dapat mengurangi kenyamanan pengunjung dalam beraktivitas, ketersediaan fasilitas yang ada kurang memadai, dan kebersihan di sekitar area tapak yang masih dianggap kurang. Beberapa kendala yang ada dapat diminimalisir dengan cara seperti menambah vegetasi peneduh yang pada tapak, menambah fasilitas yang kurang dan menyediakan fasilitas sesuai dengan kebutuhan dalam menunjang aktivitas pengunjung salah satunya seperti tempat sampah untuk menjaga kebersihan.

Berdasarkan kuesioner preferensi pengunjung, penilaian tertinggi akan digunakan dan beberapa pilihan akan dipertimbangkan yang sesuai untuk kebutuhan pada tapak untuk menunjang aktivitas pengunjung dan membantu dalam memilih apa yang perlu digunakan dalam pengembangan tapak. Hasil dari kuesioner terhadap elemen pohon yang diinginkan pengunjung menunjukkan pilihan pohon peneduh dengan contoh jenis ketapang atau cemara laut merupakan pilihan terbanyak dengan persentase (67\%). Pohon peneduh dengan jenis pohon ketapang dapat dipertimbangkan dalam pengembangan promenade ini karena merupakan vegetasi pesisir pantai dan sesuai dengan kebutuhan pada tapak yang perlu manambah pohon peneduh untuk meningkatkan tingkat kenyamanan pengunjung dalam beraktivitas. Hasil dari kuesioner pada fasilitas yang diinginkan pengunjung seperti lampu, tempat duduk, papan pemberitahuan merupakan pilihan terbanyak dengan persentase $(64 \%)$. Beberapa pilihan fasilitas tambahan lainya yang dapat dipertimbangkan sesuai kebutuhan dalam pengembangan promenade ini seperti, gazebo, tempat sampah, dan rak parkir untuk sepeda.

\subsubsection{Visual}

Pantai Padang Galak memiliki pemandangan yang bagus dan terdapat promenade pada pinggir pantai yang sering digunakan para pengunjung untuk beraktivitas seperti berjalan santai, jogging, bersepeda, dan berekreasi. Potensi yang dapat dikembangkan dari adanya promenade di pinggir pantai ini yaitu penataan vegetasi pada pinggiran promenade untuk meningkatkan nilai estetika serta bertujuan untuk menunjang kenyamanan pengunjung dalam melakukan aktivitas pada tapak.

Kendala yang terdapat pada tapak ini yaitu pada beberapa titik di pinggir promenade ditumbuhi oleh berbagai jenis vegetasi seperti semak, rerumputan, dan tanaman merambat. Keberadaan vegetasi yang tumbuh pada pinggir promenade ini terlihat tidak menarik dan mengurangi nilai estetika. Promenade ini akan dikembangkan dan diperlebar beberapa meter agar sesuai dengan ketentuan Time Saver Standards for Landscape Architecture (Harris dan Dines, 1998) untuk ukuran yang bisa digunakan jalur bersepeda, jalan santai dan jogging. Sesuai dengan sintesis promenade ukuran yang digunakan yaitu mencapai 4,6 m. Pelebaran promenade tersebut akan dapat meminimalisir kendala yang ada pada tapak dikarenakan vegetasi di pinggir promenade dan mengurangi nilai estetika akan dihilangkan dan dialihfungsikan untuk menambah lebar promenade. Beberapa vegetasi berjenis tanaman merambat yang ada pada tapak seperti katang-katang (Ipomoea pes-caprae) dan kacang laut (Canavalia maritime) akan dipertahankan serta digunakan karena merupakan tanaman asli pesisir pantai serta memiliki nilai estetika.

\subsubsection{Fasilitas Promenade}

Promenade Pantai Padang Galak pada lokasi penelitian ini memiliki kendala dimana hanya terdapat beberapa fasilitas seperti papan pemberitahuan, tempat sampah serta lampu penerangan yang hanya ada di bagian area awal memasuki kawasan pantai saja dan belum mencangkup keseluruhan bagian promenade Pantai Padang Galak. Berdasarkan hasil kuesioner pada analisis sintesis pengunjung, fasilitas yang diinginkan oleh pengunjung dan dapat dipertimbangkan untuk dapat dikembangkan adalah gazebo, tempat duduk, rak parkir sepeda dan penambahan lampu penerangan, tempat sampah, serta papan pemberitahuaan.

Fasilitas seperti lampu penerangan perlu ditambahkan dikarenakan masih banyak lokasi area promenade yang gelap dan perlu penerangan terutama di bagian selatan yang tidak ada lampu penerangan. 
Papan pemberitahuan merupakan fasilitas yang sering dijumpai pada ruang pejalan kaki umumnya, papan pemberitahuan berfungsi mengingatkan pengunjung untuk menjaga kebersihan, tidak merusak lingkungan sekitar dan lain sebagainya. Papan pemberitahuan pada Pantai Padang Galak hanya terdapat di bagian utara promenade di area awal memasuki pantai dan perlu ditambahkan untuk dapat mencangkup keseluruhan area promenade. Tempat sampah pada lokasi penelitian hanya ada di bagian utara promenade di area awal memasuki pantai. Pada bagian selatan di beberapa titik promenade terdapat timbulan sampah sehingga perlu penambahan tempat sampah untuk memfasilitasi pengunjung agar membuang sampah pada tempatnya. Tempat sampah diletakkan pada bagian tempat peristirahatan dekat dengan gazebo. Promenade Pantai Padang Galak ini sering digunakan pengunjung untuk bersepeda, untuk lebih memudahkan dan lebih tertata dalam memarkir sepeda perlu adanya fasilitas seperti rak parkir sepeda dibeberapa titik lokasi tapak. Pengunjung yang datang ke lokasi tapak banyak yang melakukan aktivitas olahraga seperti jogging, bersepeda, jalan santai dan duduk santai untuk menikmati pemandangan pantai. Aktivitas yang dilakukan tersebut perlu difasilitasi dengan menyediakan tempat duduk dan gazebo sehingga pengunjung dapat beristirahat maupun duduk saat menikmati pemandangan sekitar pantai. Terdapat lokasi yang cukup bagus untuk penempatan fasilitas peristirahatan ini yaitu pada bagian awal promenade yang dekat taman cemara yang merupakan bagian awal memasuki Pantai Padang Galak dan pada bagian selatan promenade yang dekat dengan Pantai Matahari Terbit.

Berdasarkan data Badan Penanggulangan Bencana Daerah (BPBD) Provinsi Bali (2017) pada Peta Evakuasi Tsunami Sanur, pantai selatan Bali merupakan daerah rawan bencana seperti tsunami. Lokasi dengan zona resiko bahaya tinggi Kota Denpasar diantaranya, yaitu Pantai Serangan, Pantai Sanur, Pantai Matahari Terbit dan juga Pantai Padang Galak. Danger signal seperti daerah rawan bencana tsunami tersebut sudah diantisipasi dengan pemasangan rambu peringatan rawan bencana tsunami di beberapa titik seperti Pantai Matahari Terbit dan Pantai Serangan. Papan tanda jalur evakuasi menuju lokasi yang aman sudah ada pada Pantai Padang Galak namun hanya terdapat di bagian area awal memasuki pantai saja. Promenade bagian selatan yang dekat dengan Pantai Matahari Terbit belum tersedia sehingga perlu ditambahkan guna memudahkan pengunjung menuju lokasi yang aman.

Analisis dan sintesis dari potensi, kendala, amenity, serta sintesis yang telah dirangkum dapat dilihat pada Tabel 1.

Tabel 1. Analisis dan Sintesis

\begin{tabular}{|c|c|c|c|c|c|c|}
\hline \multirow[t]{2}{*}{ No } & \multirow[t]{2}{*}{ Aspek } & \multicolumn{4}{|c|}{ Analiasis } & \multirow{2}{*}{$\begin{array}{c}\text { Sintesis } \\
\text { Pemecahan dan } \\
\text { pemanfaatan }\end{array}$} \\
\hline & & Potensi & Kendala & Amenity & $\begin{array}{c}\text { Danger } \\
\text { signal }\end{array}$ & \\
\hline 1 & Promenade & $\begin{array}{l}\text { Dikembangkan } \\
\text { sebagai area } \\
\text { rekreasi dan } \\
\text { olahraga }\end{array}$ & $\begin{array}{l}\text { - Pengunjung } \\
\text { mengendarai } \\
\text { dan } \\
\text { memarkirkan } \\
\text { sepeda motor } \\
\text { - Area tapak } \\
\text { kurang lebar }\end{array}$ & & & $\begin{array}{l}\text { - Mengurangi sedikit } \\
\text { timbunan tanah di } \\
\text { pinggir tapak yang } \\
\text { mudah dilalui sepeda } \\
\text { motor } \\
\text { - Pelebaran tapak sesuai } \\
\text { ketentuan untuk lebar } \\
\text { area berjalan kaki dan } \\
\text { bersepeda }\end{array}$ \\
\hline 2 & Vegetasi & $\begin{array}{l}\text { Terdapat } \\
\text { vegetasi asli } \\
\text { pesisir yang } \\
\text { dapat } \\
\text { digunakan } \\
\text { dalam } \\
\text { penataan }\end{array}$ & $\begin{array}{l}\text { Vegetasi } \\
\text { peneduh yang } \\
\text { kurang pada } \\
\text { tapak }\end{array}$ & $\begin{array}{l}\text { Memiliki suhu ideal } \\
\text { dengan rata-rata } 27,5^{\circ} \mathrm{C} \text {, } \\
\text { pada suhu maksimum } \\
\text { mencapai } 37,0^{\circ} \mathrm{C} \text { dapat } \\
\text { membuat lokasi tapak } \\
\text { terasa panas }\end{array}$ & & $\begin{array}{l}\text { Penambahan vegetasi } \\
\text { peneduh }\end{array}$ \\
\hline
\end{tabular}


Lanjutan Tabel 1. Analisis dan Sintesis

\begin{tabular}{|c|c|c|c|c|c|c|}
\hline \multirow[t]{2}{*}{ No } & \multirow[t]{2}{*}{ Aspek } & \multicolumn{4}{|c|}{ Analiasis } & \multirow{2}{*}{$\begin{array}{c}\text { Sintesis } \\
\text { Pemecahan dan } \\
\text { pemanfaatan }\end{array}$} \\
\hline & & Potensi & Kendala & Amenity & $\begin{array}{l}\text { Danger } \\
\text { signal }\end{array}$ & \\
\hline 3 & Pengunjung & & $\begin{array}{l}\text { Hasil Kuesioner: } \\
\text { - Kurangnya } \\
\text { vegetasi peneduh } \\
\text { - Kurangnya } \\
\text { fasilitas } \\
\text { - Kebersihan yang } \\
\text { masih dianggap } \\
\text { kurang }\end{array}$ & & & $\begin{array}{l}\text { - Penambahan vegetasi } \\
\text { peneduh } \\
\text { - Penambahan fasilitas } \\
\text { penunjang } \\
\text { - Penambahan fasilitas } \\
\text { seperti tempat sampah } \\
\text { untuk menjaga } \\
\text { kebersihan }\end{array}$ \\
\hline 4 & Visual & $\begin{array}{l}\text { Area tapak } \\
\text { dapat ditata } \\
\text { dari segi tata } \\
\text { hijau }\end{array}$ & $\begin{array}{l}\text { Terdapat area } \\
\text { tapak yang } \\
\text { ditumbuhi } \\
\text { vegetasi yang } \\
\text { terlihat kurang } \\
\text { baik } \\
\text { Fasilitas hanya di }\end{array}$ & & & $\begin{array}{l}\text { Area vegetasi yang } \\
\text { memiliki visual kurang } \\
\text { baik akan digunakan } \\
\text { sebagai area pelebaran } \\
\text { tapak dan ditata }\end{array}$ \\
\hline 5 & $\begin{array}{l}\text { Fasilitas } \\
\text { Promenade }\end{array}$ & & $\begin{array}{l}\text { bagian awal } \\
\text { memasuki pantai } \\
\text { saja sedangkan di } \\
\text { bagian selatan } \\
\text { belum tersedia } \\
\text { fasilitas }\end{array}$ & & $\begin{array}{l}\text { Merupakan } \\
\text { pantai } \\
\text { selatan Bali } \\
\text { yang } \\
\text { terdampak } \\
\text { tsunami }\end{array}$ & $\begin{array}{l}\text { Menambah fasilitas di } \\
\text { bagian selatan termasuk } \\
\text { papan jalur evakuasi } \\
\text { menuju lokasi yang aman } \\
\text { dan menambah fasilitas } \\
\text { penunjang berdasarkan } \\
\text { hasil kuesioner }\end{array}$ \\
\hline
\end{tabular}

\subsection{Konsep}

\subsubsection{Konsep Dasar}

Konsep dasar dalam rencana penataan ini yaitu, area promenade yang diperuntukkan mewadahi pengunjung dalam melakukan aktivitas rekreasi dan olahraga. Aktivitas rekreasi ini seperti jalan santai, dan duduk santai menikmati pemandangan. Aktivitas olahraga yang dilakukan pada promenade ini seperti jogging dan bersepeda. Konsep dasar pada rencana ini dikembangkan menjadi konsep pengembangan.

\subsubsection{Konsep Pengembangan}

Konsep pengembangan promenade Pantai Padang Galak meliputi konsep ruang, konsep sirkulasi, dan konsep tata hijau. Konsep ruang dalam rencana penataan promenade Pantai Padang Galak membagi ruang menjadi dua area yang dibedakan berdasarkan peruntukkannya. Konsep ruang ini meliputi ruang aktif yang peruntukkannya sebagai area aktivitas dan ruang pasif yang peruntukkannya sebagai area vegetasi serta fasilitas. Sirkulasi promenade Pantai Padang Galak ini menggunakan konsep sirkulasi dalam ruang dan sirkulasi antar ruang. Sirkulasi dalam ruang menghubungkan antara satu ruang aktif dengan ruang aktif lainnya. Sirkulasi antar ruang menghubungkan antara ruang aktif dengan ruang pasif. Sirkulasi pada promenade ini dibedakan menjadi dua bentuk sistem sirkulasi, yaitu sistem sirkulasi khusus untuk jogging dan pejalan kaki serta sistem sirkulasi khusus untuk bersepeda. Konsep tata hijau yang direncanakan untuk promenade Pantai Padang Galak ini yaitu penggunaan tanaman yang memiliki fungsi estetika dan fungsi perindang pesisir pantai. Konsep tata hijau ini mempertimbangkan jenis tanaman yang mampu beradaptasi dengan lingkungan daerah pantai.

\subsection{Rencana Penataan}

Rencana Penataan merupakan hasil yang dibuat berdasarkan pada konsep pengembangan yang menghasilkan rencana tata ruang, rencana tata sirkulasi, rencana tata hijau, dan produk akhir rencana penataan ini yaitu rencana tapak.

Rencana tata ruang merupakan pengembangan dalam rencana penataan untuk pembagian area ruang yang sesuai keadaan tapak dengan menerapkan konsep yang telah ditetapkan. Ruang tersebut dikelompokkan menjadi zona pasif dan zona aktif. Zona pasif merupakan area yang difungsikan untuk tidak melakukan aktivitas contohnya seperti tempat beristirahat, area vegetasi, dan penempatan fasilitas. Zona aktif merupakan area yang difungsikan untuk melakukan aktivitas contohnya seperti jalan santai, jogging, dan 
bersepeda. Rencana tata ruang yang dikembangkan pada area promenade Pantai Padang Galak dapat dilihat pada Gambar 3.

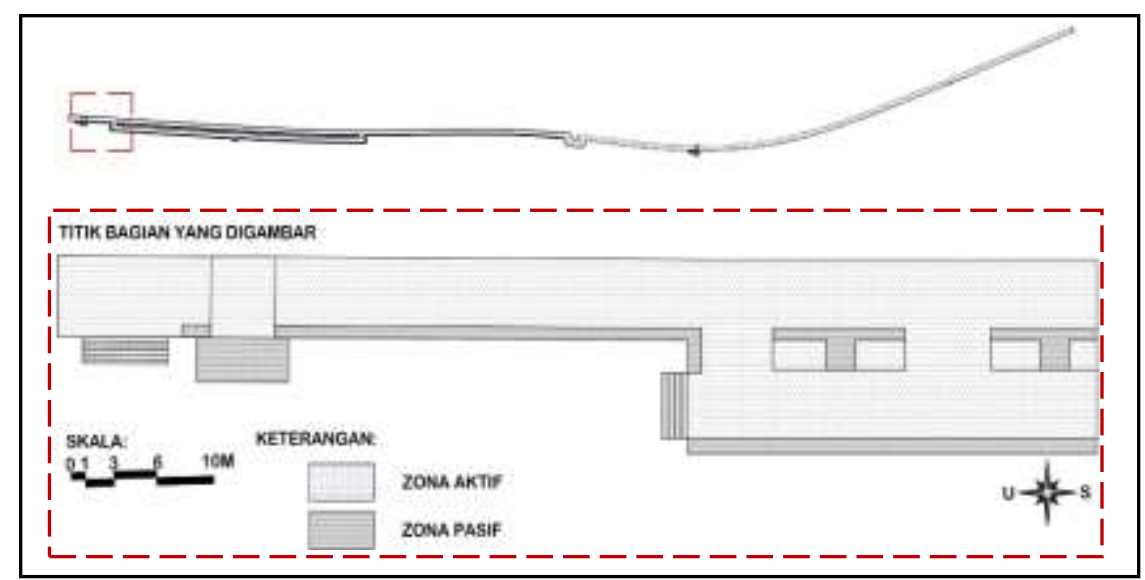

Gambar 3. Rencana Tata Ruang

Rencana tata sirkulasi dibuat sesuai dengan analisis aktivitas pengguna tapak. Promenade Pantai Padang Galak menggunakan dua jenis sistem sirkulasi. Sirkulasi yang digunakan yaitu jenis sistem sirkulasi untuk pejalan kaki (aktivitas jogging) dan sistem sirkulasi untuk bersepeda. Berdasarkan pada tahap analisis dan sintesis ukuran minimum promenade untuk jalur pejalan kaki dan pesepeda pada ketentuan Time Saver Standards for Landscape Architecture (Harris dan Dines, 1998) yaitu $3 \mathrm{~m}$. Lebar ukuran minimum tersebut akan dikembangkan hingga mencapai lebar 4,6 $\mathrm{m}$ yang termasuk lebar sirkulasi pada jembatan dengan ukuran yang sama. Penataan promenade ini terbagi atas dua sirkulasi berbeda yaitu sirkulasi untuk pejalan kaki dengan ukuran lebar 2,2 $\mathrm{m}$ dan sirkulasi untuk pesepeda dengan ukuran lebar 2,4 $\mathrm{m}$. Bagian utara promenade yang dekat dengan taman cemara terdapat area yang cukup luas di pinggirnya yang dapat dikembangkan dalam penataan promenade ini sebagai tambahan sirkulasi untuk jalur pejalan kaki dan pesepeda. Sesuai dengan konsep sirkulasi rencana pada jalur promenade ini akan dibuat area pemberhentian yang difungsikan untuk memudahkan pengguna sepeda maupun pejalan kaki untuk melintasi antar area tersebut menuju pada titik untuk bersitirahat serta menuju tempat untuk memarkirkan sepeda pada saat keadaan ramai. Faslitas yang disediakan yaitu tempat duduk dan gazebo. Sirkulasi pada promenade ini akan diberi tanda berupa gambar sebagai jalur untuk area pejalan kaki dan pengguna sepeda serta tanda berupa garis yang dibuat pada bagian tengah promenade sebagai batas antar jalur. Rencana tata sirkulasi dapat dilihat pada Gambar 4.

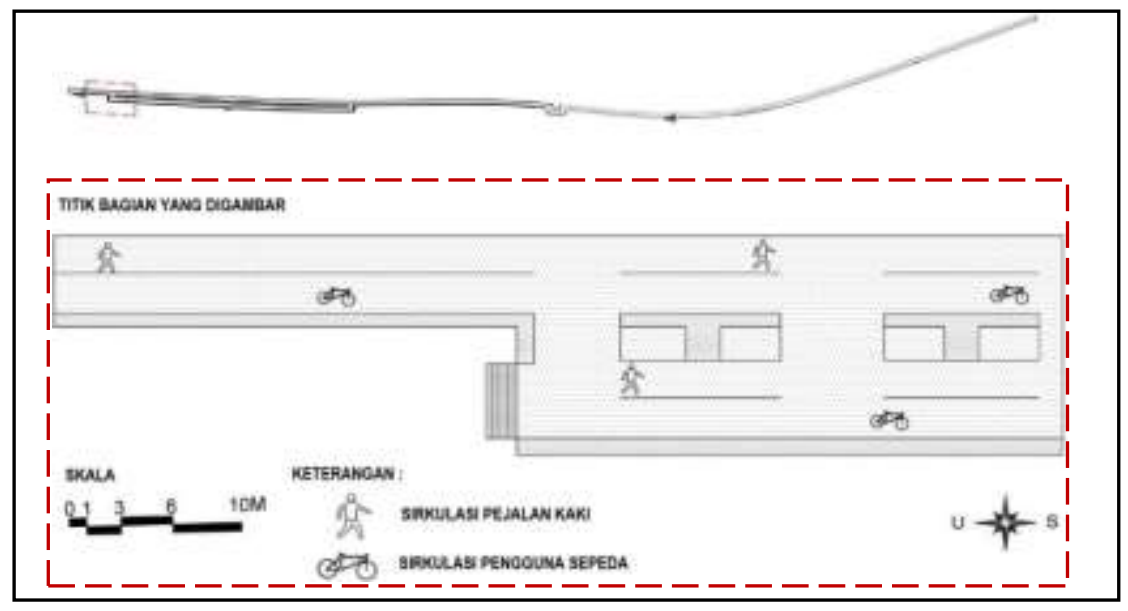

Gambar 4. Rencana Tata Sirkulasi

Tata hijau difungsikan sebagai aspek estetika dan kenyamanan. Aspek estetika ini memberi kesan keindahan secara visual dan aspek kenyamanan yaitu sebagai peneduh dari teriknya sinar matahari. Pemilihan 
vegetasi untuk rencana tata hijau ini diprioritaskan pada tanaman yang dapat menyesuaikan dengan lingkungan pesisir pantai. Berdasarkan pada tahap analisis dan sintesis penelitian vegetasi yang dapat dipertimbangkan untuk digunakan sebagai rencana tata hijau promenade Pantai Padang Galak ini berupa jenis tanaman pohon dan penutup tanah. Jenis tanaman yang digunakan yaitu tanaman yang sudah terdapat pada tapak seperti, ketapang (Terminalia catappa), kacang laut (Canavalia maritime), serta katang-katang (Ipomoea pes-caprae) dan tambahan penggunaan tanaman yang bukan dari tapak penelitian yaitu, bakungan (Hymenocalis littoralis).

Penggunaan pohon ketapang dikarenakan pada lokasi penelitian kurang tanaman peneduh dan memiliki bentuk tekstur percabangan yang bagus. Pemilihan tanaman ini sesuai dengan karakteristik daerah tersebut yang berada di pinggir pantai. Bakungan atau bakung air mancur (Hymenocalis littoralis) merupakan tanaman penutup tanah yang memiliki bentuk bunga seperti laba-laba berwarna putih. Pemilihan tanaman bakungan ini digunakan pada bagian area penanaman sebagai peningkat nilai estetika karena memiliki bunga dan bentuk seperti air mancur yang dapat memperindah tapak. Jenis tanaman ini digunakan sebagai tambahan pada rencana penataan karena dapat tumbuh baik pada lingkungan pinggir pantai, di beberapa pantai contohnya seperti Pantai Matahari Terbit dan Pantai Sanur menggunakan tanaman ini untuk memperindah pada pinggir area pejalan kaki tersebut. Kacang laut (Canavalia maritime) dan Katang-katang (Ipomoea pescaprae) merupakan tanaman penutup tanah. Berdasarkan inventarisasi tanaman ini ada di pinggir area promenade Pantai Padang Galak. Penggunaan tanaman ini dimaksudkan sebagai bentuk konservasi tanaman asli daerah pesisir pantai serta mempunyai nilai estetika terlihat dari bentuk tanaman yang memiliki bunga yang indah. Rencana tata hijau dapat dilihat pada Gambar 5.

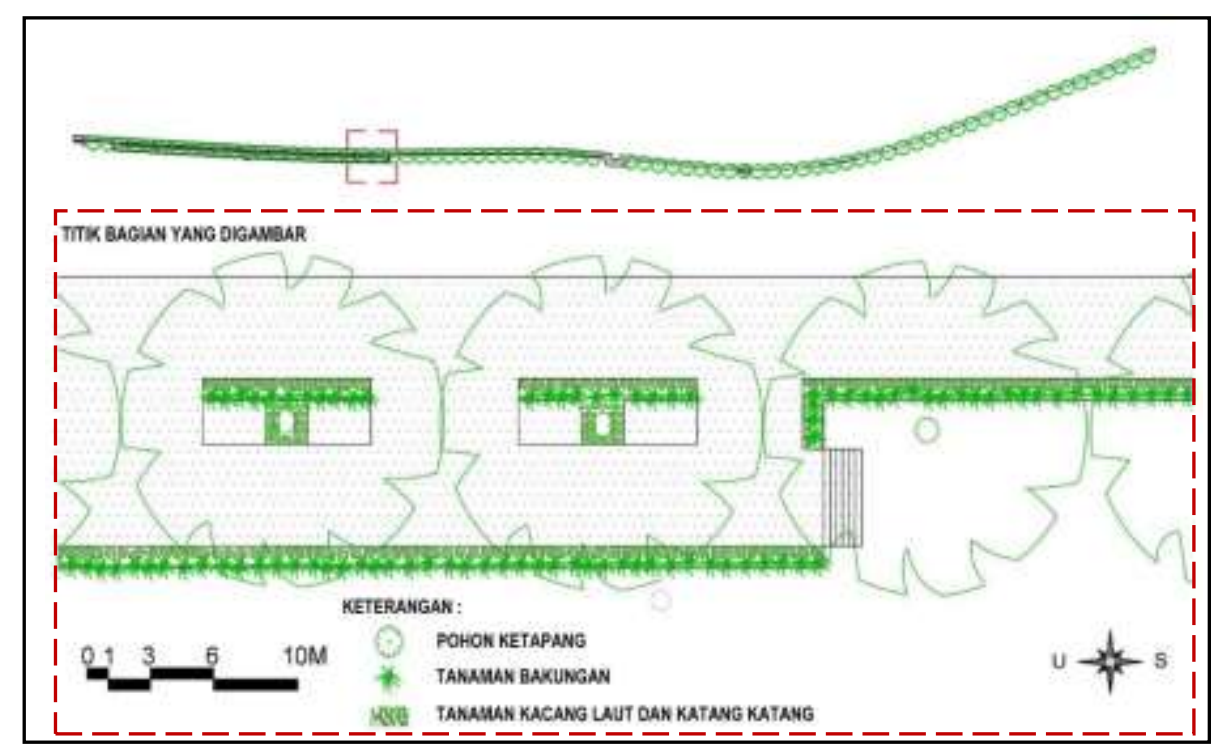

Gambar 5. Rencana Tata Hijau

Tahap Rencana tapak ini merupakan hasil akhir berupa gambar secara detail. Gambar rencana tapak ini merupakan keseluruhan aspek yang meliputi rencana tata ruang, rencana tata sirkulasi, rencana tata hijau dan letak fasilitas penunjang. Rencana tapak dapat dilihat pada Gambar 6. 


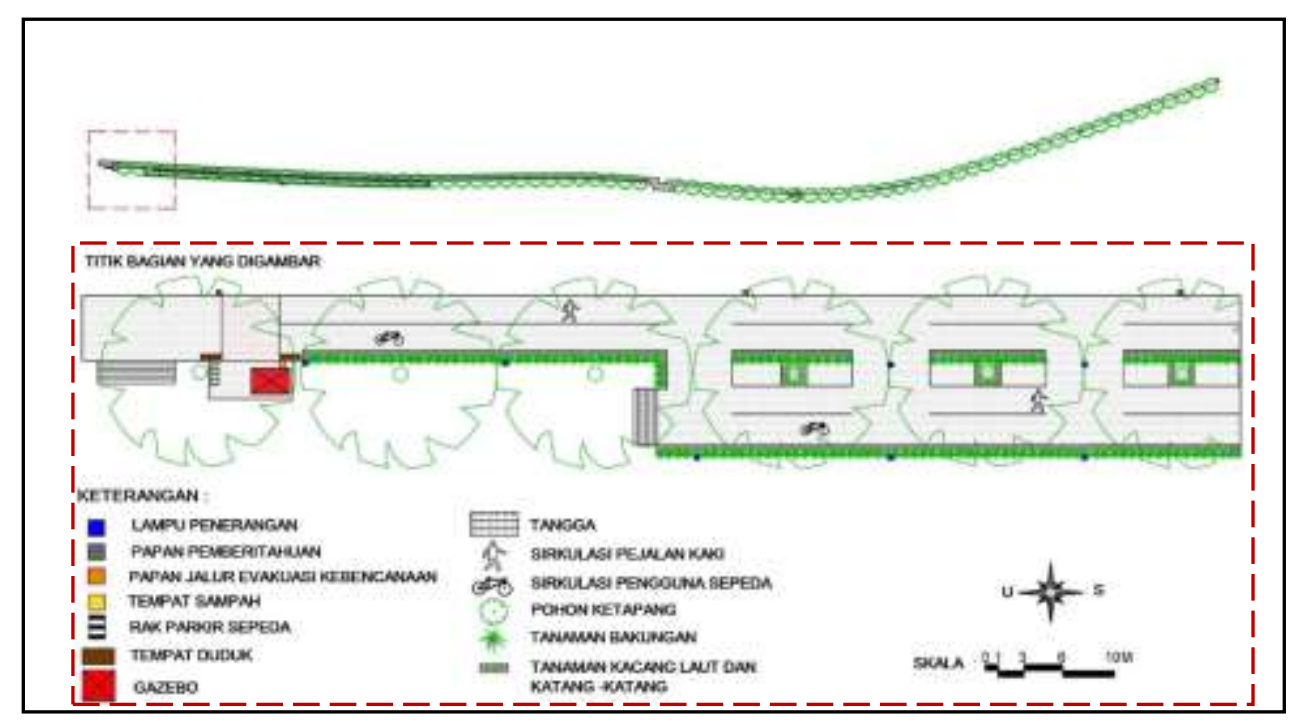

Gambar 6. Rencana Tapak

\section{Simpulan dan Saran}

\subsection{Simpulan}

Rencana penataan promenade pantai ini terbagi menjadi dua ruang yaitu ruang aktif dan ruang pasif. Sirkulasi pada penataan promenade ini dipisah antara pengguna sepeda dengan pejalan kaki. Tata hijau diperlukan dalam menata area pada tapak lokasi penelitian. Vegetasi yang digunakan berupa pohon seperti ketapang (Terminalia catappa) yang berfungsi sebagai peneduh dan vegetasi berupa penutup tanah seperti bakungan (Hymenocalis littoralis), kacang laut (Canavalia maritime) serta katang-katang (Ipomoea pescaprae) yang difungsikan untuk memperindah tapak. Fasilitas pada penataan ini diperlukan untuk menunjang kebutuhan beraktivitas para pengunjung, beberapa fasilitas belum terdapat pada lokasi penelitian. Fasilitas yang dikembangkan serta ditambahkan yaitu berupa gazebo, tempat duduk, rak parkir sepeda, serta penambahan papan pemberitahuan, lampu penerangan, tempat sampah dan papan tanda jalur evakuasi kebencanaan.

\subsection{Saran}

Rencana penataan dari penelitian ini merupakan penataan promenade dari segi kenyamanan dan penambahan fasilitas penunjang bagi pengguna dalam melakukan aktivitas. Perlu penelitian lebih lanjut mengenai bentuk desain permukaan perkerasan untuk lebih menambah kesan menarik tampilan tapak dan perlu lebih memperkuat permukaan perkerasan pada area promenade Pantai Padang Galak.

\section{Daftar pustaka}

Badan Pusat Statistik (BPS) Kota Denpasar. 2017. Kota Denpasar dalam Angka. Badan Pusat Statistik Kota Denpasar.

Balai Wilayah Sungai Bali-Penida. 2017. Tanggul Pengaman Pantai dan Promenade Pantai Padang Galak. Harris, C. W. \& N. T. Dines. 1998. Time-Saver Standards for Landscape Architecture 2* ed. McGraw-Hill Companies. New York.

Dinas Hidro-Oseanografi TNI Angkatan Laut. 2017. Daftar Pasang Surut Kepulauan Indonesia. Laurie. 1986. Pengantar Kepada Arsitektur Pertamanan (terjemahan). Intermata. Bandung.

Badan Penanggulangan Bencana Daerah (BPBD) Provinsi Bali. 2017. Peta Evakuasi Tsunami Sanur, Denpasar. Tersedia online pada http://bpbd.baliprov.go.id/?page=Peta-EvakuasiTsunami\&language=id\&domain (diakses pada 9 Maret 2018). 